\title{
Selective serotonin reuptake inhibitors and the risk of hepatocellular carcinoma in hepatitis $B$ virus-infected patients
}

This article was published in the following Dove Press journal: Cancer Management and Research

\author{
Chia-Ming Chang ${ }^{1-3}$ \\ Ming-Shun Hsieh ${ }^{1-4}$ \\ Tsung-Chieh Yang ${ }^{3,5}$ \\ Vivian Chia-Rong $\mathrm{Hsieh}^{6}$ \\ Jen-Huai Chiang ${ }^{7}$ \\ Hsien-Hao Huang 1,3 \\ Chorng-Kuang How ${ }^{1,3}$ \\ Sung-Yuan $\mathrm{Hu}^{8}$ \\ David Hung-Tsang Yen ${ }^{1,3}$ \\ 'Department of Emergency \\ Medicine, Taipei Veterans General \\ Hospital, ${ }^{2}$ Institute of Occupational \\ Medicine and Industrial Hygiene, \\ National Taiwan University \\ College of Public Health, ${ }^{3}$ College \\ of Medicine, National Yang-Ming \\ University, Taipei, ${ }^{4}$ Department of \\ Emergency Medicine, ${ }^{5}$ Division of \\ Gastroenterology, Department of \\ Internal Medicine, Taipei Veterans \\ General Hospital, Taoyuan Branch, \\ Taoyuan, ${ }^{6}$ Department of Health \\ Services Administration, ${ }^{7}$ Management \\ Office for Health Data, China Medical \\ University, ${ }^{8}$ Department of Emergency \\ Medicine, Taichung Veterans General \\ Hospital, Taichung, Taiwan, Republic \\ of China
}

Correspondence: Ming-Shun Hsieh Department of Emergency Medicine, Taipei Veterans General Hospital, Taoyuan Branch, No. 100, Sec. 3, ChengKung Rd., Taoyuan District, Taoyuan City 330, Taiwan, Republic of China

Tel +8863286800 I

Fax +88633335211

Email simpleabei@yahoo.com.tw
Background: This study aimed to investigate the association between the use of selective serotonin reuptake inhibitors (SSRIs) and the risk of hepatocellular carcinoma (HCC) in patients with chronic hepatitis B virus (HBV) infection.

Methods: We conducted a population-based cohort study by using claims data from the Taiwan National Health Insurance Research Database (NHIRD). The study cohort comprised 1380 newly diagnosed HBV-infected patients with SSRI use who were frequency matched by age, sex, liver cirrhosis, and index year with HBV-infected patients without SSRI use in the comparison cohort. Each patient case was followed from 2000 to 2012 to identify incident HCC cases. Cox proportional hazards regression was performed to evaluate the association between SSRI use and HCC risk. The further sensitivity analysis used case-control study design. A total of 9070 HCC subjects retrieved from NHIRD, and equal non-HCC subjects were analyzed after matching for age and sex.

Results: We identified 9 and $24 \mathrm{HCC}$ cases in the study and comparison cohorts during the follow-up period of 7056 and 6845 person-years, respectively. The incidence rate of HCC was 1.28 and 3.51 per 1000 person-years for SSRI and non-SSRI users, respectively. After adjusting for potential confounders, the adjusted hazard ratio (HR) for SSRI use was 0.28 ( $95 \%$ confidence interval [CI], 0.12-0.64; $p=0.0027$ ). For SSRI users with a cumulative defined daily dose (cDDD) of $28-89,90-364$, and $\geq 365$, the adjusted HRs were $0.51,0.22$, and 0.12 , respectively, (95\% CI, 0.21-1.25, 0.05-0.94, and 0.02-0.90, respectively) compared with non-SSRI users ( $<28$ cDDD). The sensitivity analysis showed that the SSRI presented with a dose-response protective effect for HCC in the multivariate analysis.

Conclusion: SSRIs use may possibly reduce the risk of HCC in HBV-infected patients in a dose-responsive manner.

Keywords: selective serotonin reuptake inhibitors, SSRI, hepatitis B virus, HBV, hepatocellular carcinoma, HCC, depression

\section{Introduction}

Serotonin, also known as 5-hydroxytryptamine (5-HT), is a biogenic amine derived from tryptophan that functions as a ligand for a large family of 5-HT receptors. ${ }^{1}$ Serotonin is critical for neurotransmission in the central nervous system, thus controlling mood, behavior, sleep, and anxiety. Selective serotonin reuptake inhibitors (SSRIs) are the most widely prescribed medication for treating depression because they are considered safe and well-tolerated compared with earlier generation antidepressants, such as tricyclic antidepressants and monoamine oxidase inhibitors. ${ }^{2,3}$ 
Hepatitis B virus (HBV) infection typically leads to chronic hepatitis, often following a progressive course over decades, finally resulting in cirrhosis and hepatocellular carcinoma (HCC). In Taiwan, the prevalence of viral hepatitis has been high, and the prevalence of chronic infections was $15-20 \%$. HBV carriers are at a substantially increased risk of HCC and liver-related death compared with people without HBV infection. ${ }^{4-6}$

Depression is a common disorder in patients with chronic hepatitis $\mathrm{C}$ virus (HCV) infection undertaking interferon therapy. ${ }^{7}$ Certain SSRIs have been reported to be safe and effective in treating such patients. ${ }^{8,9}$ In a study involving $783 \mathrm{HCV}$-infected patients, $63 \%$ had depression and $38 \%$ were on antidepressants, mostly SSRI. ${ }^{10}$ In addition, patients with cirrhosis were depressed more frequently, and were more likely to take antidepressants. ${ }^{11}$ A large section of the hepatitis population in Taiwan was possibly exposed to SSRI-based antidepressants; therefore both low and high risks associated with serious adverse effects such as HCC development should be evaluated with care. Current studies on SSRI use in HBV-infected patients, particularly on the association between SSRI use and the risk of HCC, are lacking. Furthermore, although many preclinical studies have been conducted, no definite conclusion has been reached on the association between serotonin and HCC. As we know, the use of tricyclic antidepressants and SSRIs was related to the lower risk for $\mathrm{HCC} .{ }^{12} \mathrm{~A}$ recent larger case-control study showed the association between SSRI and decreased risk of HCC in a dose-dependent manner. ${ }^{13}$ However, no present study showed the association between HBV-infected patients and SSRI use.

For the present study, we aimed to determine the association between SSRI use and the risk of HCC in patients with chronic HBV infection in Taiwan by using the Taiwan National Health Insurance Research Database (NHIRD).

\section{Methods}

\section{Data sources}

We conducted a nationwide population-based cohort study by using data from the NHIRD. The National Health Insurance program in Taiwan was launched on March 1, 1995, by the National Health Insurance Administration (NHIA), and provided coverage to more than 23.03 million residents in Taiwan (approximately $99.2 \%$ of the population). The NHIA released identification-encrypted data to the National Health Research Institute (NHRI) to establish the NHIRD. The Longitudinal Health Insurance Database 2000 (LHID2000), used in this study, contains medical information of 1 million beneficiaries randomly sampled from the registry of all beneficiaries in 2000. Claims data in the LHID2000 were extended from January 1, 1996 to December 31, 2011. Age- and sex-related distributions in the original claims data and the sampled data do not differ significantly. The International Classification of Diseases, Ninth Revision, Clinical Modification (ICD-9-CM) codes were used for diagnoses.

The NHIRD contains admission and outpatient visit data, including information on patient characteristics, such as age; sex; date of admission, discharge, and outpatient visits; and 5 main discharge or 3 outpatient visit diagnoses (according to ICD-9-CM codes). In addition, the data files contain information on drug prescriptions, including the names of prescribed drugs and dosage. The data in the NHIRD are of high quality, and their validity has been proved in several studies. ${ }^{14-16}$

The NHRI scrambles patient identification and replaces it with surrogate numbers to ensure privacy. Furthermore, data confidentiality is maintained in accordance with NHIA and NHRI data regulations. Because the NHIRD contains de-identified secondary data for research, our study was exempted from the informed consent of participants. This study was approved by the Institutional Review Board of China Medical University (CMUH104-REC2-115).

\section{Study population and outcomes}

Patients aged $\geq 20$ years and $<100$ years newly diagnosed with HBV infection (ICD-9-CM: 070.2, 070.3, and V02.61) between January 1, 2000 and December 31, 2010 were recruited. Patients with concurrent HCV infection (ICD9-CM: 070.41, 070.44, 070.51, 070.54, 070.7, and V02.62), those with newly diagnosed HCC (ICD-9-CM: 155.0) within 1 year of $\mathrm{HBV}$ infection, those with a history of malignancy diseases including HCC, and those with a follow-up duration $<1$ year or with missing data were excluded. HCC cases were identified and confirmed through the registration in the Catastrophic Illness Patient Database, a subset of the NHIRD. ${ }^{17-19}$

The initiation date of SSRI use in HBV-infected patients was defined as the index date for the study cohort. For comparison, a random date was assigned to the patients in the comparison cohort for matching, with the same period in years between the new diagnosis of HBV infection and index date.

\section{SSRI exposure}

The SSRIs of interest in this study were citalopram, escitalopram, fluoxetine, fluvoxamine, paroxetine, and sertraline. We identified patients who received SSRI prescriptions in 
the outpatient visit from January 1, 2000 to the date of HCC diagnosis or the end of follow-up. The defined daily dose (DDD) recommended by the World Health Organization is a unit for measuring a prescribed drug amount. DDD is the assumed average maintenance dose per day of a drug consumed for its main indication in adults. We can compare SSRIs while maintaining the same standard by using the following formula: (total amount of drug) / (amount of drug in a DDD) = number of DDDs. Cumulative DDD (cDDD), indicating the total exposed dosage, was used to estimate the sum of dispensed DDD of any SSRI. Tsan et al used this definition to investigate the association between statins and HCC risk in patients with HBV and HCV infections. ${ }^{15,16}$ To examine the dose-responsive relationship, we categorized the cumulative dose of SSRI into 4 groups $(<28,28-89$, 90-364, and $\geq 365$ cDDD) because the duration of the refill card in Taiwan was 3 months. Patients with $<28$ cDDD SSRI use during the study period were defined as non-SSRI users. In this study, the SSRI cumulative doses were categorized into 3 groups (28-89, 90-364, and $\geq 365)$ and put into the linear regression model as continuous variables to estimate the $p$-value for trend.

\section{Potential confounders}

We systematically identified the potential confounders for HCC by referring to the ICD-9-CM codes in the claims data: alcohol-related disease (ARD) (ICD-9-CM: 291, 303.0, 303.9, 305.0, and 571.0-571.3), liver cirrhosis (ICD9-CM: 571.2, 571.5, 571.6, 572.2-572.4, 572.8, and 573.0), hypertension (HTN) (ICD-9-CM: 401-405), hyperlipidemia (ICD-9-CM: 272.0-272.4), biliary stones (ICD-9-CM: 574), chronic kidney disease (ICD-9-CM: 581-584, 586-588, 403, 404, and 285.21), diabetes mellitus (DM) (ICD-9-CM: 250, $357.2,362.01,362.02$, and 366.41), ischemic heart disease (IHD) (ICD-9-CM: 411-414), congestive heart failure (CHF) (ICD-9-CM: 428), and peripheral arterial occlusive disease (PAOD) (ICD-9-CM: 440-444). Diagnoses given ahead of or in concurrence with the diagnosis of HBV infection were considered as underlying comorbidities. Many agents have exhibited positive results in chemoprevention for HCC. ${ }^{16,19,20}$ These potential drug confounders included antivirals (adefovir, entecavir, lamivudine, telbivudine, and interferon), statins, metformin, and aspirin.

\section{Statistical analyses}

Differences in demographic characteristics and comorbidities between the study and comparison cohorts were examined using the chi-square and 2-sample $t$-tests. Hazard ratios (HRs) with 95\% confidence intervals (95\% CIs) were calculated for each variable using Cox proportional hazards regression. Differences in the incidence of HCC development between different SSRI consumption groups $(<28,28-89$, 90-364, and $\geq 365$ cDDD) were estimated using Kaplan-Meier curves by performing the log-rank test. Statistical analyses were conducted using the SAS 9.4 statistical package (SAS Institute Inc., Cary, NC, USA), and $p<0.05$ was considered statistically significant.

\section{Results}

We recruited 2760 patients (1374 men and 1386 women) newly diagnosed with HBV infection during the study period. The study cohort comprised 1380 SSRI users who met the inclusion criteria. After frequency matching by age, sex, liver cirrhosis, and index date, an equal number of non-SSRI users comprised the comparison cohort. Figure 1 shows the selection process of participants in the study and comparison cohorts. The mean age of patients was 46.51 \pm 14.74 years and $46.26 \pm 14.33$ years in the study and comparison cohorts, respectively. The basic demographic characteristics of the study and comparison cohorts are listed in Table 1. The percentage of comorbidities including ARD, HTN, DM, and IHD was higher in the study cohort compared with the comparison cohort. The incidence rate of HCC was 1.28 and 3.51 per 1000 person-years for the study cohort and comparison cohort, respectively. The median duration between the first diagnosis of HBV and HCC was 9.52 and 8.25 years for the study and comparison cohorts, respectively.

In univariate analyses, covariates such as the male sex, age $\geq 60$ years, ARD, cirrhosis, HTN, IHD, CHF, and PAOD increased the risk of HCC (Table 2). Conversely, SSRI use reduced $\mathrm{HCC}$ risk $(\mathrm{HR}=0.36 ; 95 \% \mathrm{CI}, 0.17-0.78$; $p=0.0097)$. In multivariate analyses using Cox proportional hazards regression, SSRI use exerted a significant protective effect on HCC after adjusting for the potential confounders of age, sex, and all comorbidities (adjusted HR $=0.28 ; 95 \%$ CI, 0.12-0.64; $p=0.0027$ ).

\section{Dose-responsive relationship}

A dose-responsive relationship was noted between SSRI use and HCC risk. For SSRI users with a cDDD of 28-89, 90-364, and $\geq 365$, the adjusted HRs were $0.51,0.22$, and 0.12 , respectively, $(95 \% \mathrm{CI}, 0.21-1.25,0.05-0.94$, $0.02-0.90$, respectively) compared with non-SSRI users 


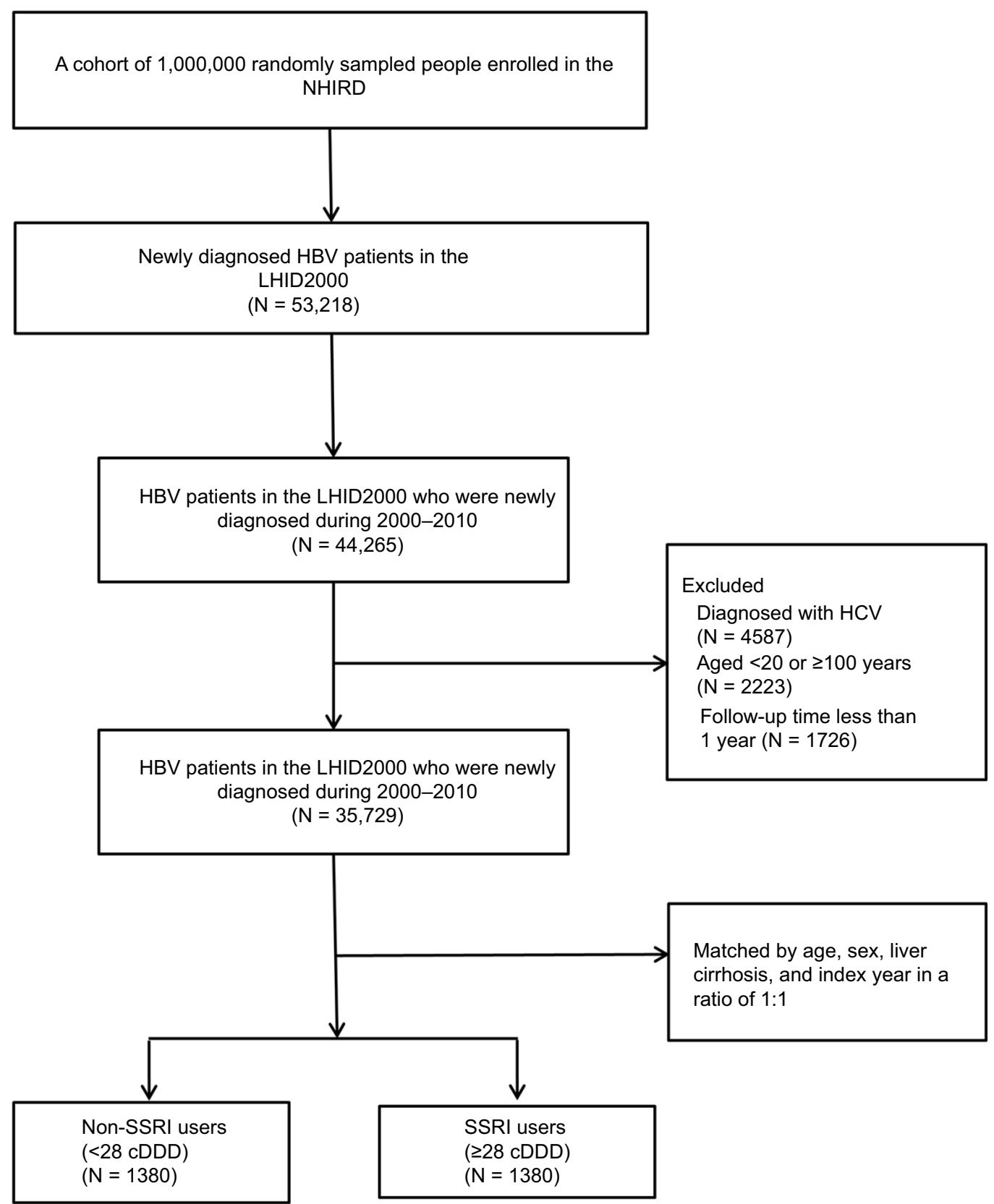

Figure I Flowchart of the patient selection process in the study (SSRI users) and comparison cohorts (non-SSRI users).

Abbreviations: cDDD, cumulative defined daily dose; HBV, hepatitis B virus; HCV, hepatitis C virus; LHID2000, Longitudinal Health Insurance Database 2000; NHIRD, National Health Insurance Research Database; SSRI, selective serotonin reuptake inhibitor.

( $<28$ cDDD). Kaplan-Meier curves of the 4 cDDD groups for the study and comparison cohorts, estimated by conducting the log-rank test, differed significantly (Figure 2). Furthermore, the difference was directly proportional to the follow-up duration in the 4 groups. The sensitivity analysis adjustments had little effect on the estimates of the association between SSRI use and HCC risk in different models (Table 3). The SSRI effect was dependent on the dose-responsive relationship in each cDDD subgroup within different adjustment models for metformin, statins, and aspirin (Table 4).

\section{Sensitivity analysis}

Because of the small number of HCC events in the cohort study, we further conducted a sensitivity analysis by using case-control study design. The HCC subjects were retrieved from the catastrophic illness database of NHIRD, which had been certificated in many studies. ${ }^{16} \mathrm{~A}$ total of $9070 \mathrm{HCC}$ 
Table I Demographic characteristics and comorbidities in HBV-infected SSRI and non-SSRI users

\begin{tabular}{|c|c|c|c|c|c|}
\hline \multirow[t]{3}{*}{ Variables } & \multicolumn{4}{|c|}{ Patients with HBV infection } & \multirow[t]{3}{*}{$p$-value } \\
\hline & \multicolumn{2}{|c|}{$\begin{array}{l}\text { Non-SSRI user (<28 cDDD) } \\
(n=1380)\end{array}$} & \multicolumn{2}{|c|}{$\begin{array}{l}\text { SSRI user ( } \geq 28 \text { cDDD) } \\
(n=1380)\end{array}$} & \\
\hline & $\mathbf{n}$ & $\%$ & n & $\%$ & \\
\hline Sex & & & & & 0.99 \\
\hline Female & 693 & 50.22 & 693 & 50.22 & \\
\hline Male & 687 & 49.78 & 687 & 49.78 & \\
\hline Age, years & & & & & 0.99 \\
\hline I8-39 years & 497 & 36.01 & 497 & 36.01 & \\
\hline $40-59$ years & 638 & 46.23 & 638 & 46.23 & \\
\hline$\geq 60$ years & 245 & 17.75 & 245 & 17.75 & \\
\hline Mean $(S D)^{\#}$ & 46.26 & & 46.51 & & 0.6434 \\
\hline \multicolumn{6}{|l|}{ Comorbidity } \\
\hline ARD & 32 & 2.32 & 57 & 4.13 & 0.0071 \\
\hline Cirrhosis & 45 & 3.26 & 45 & 3.26 & 0.99 \\
\hline $\mathrm{HTN}$ & 274 & 19.86 & 337 & 24.42 & 0.0039 \\
\hline Hyperlipidemia & 179 & 12.97 & 209 & 15.14 & 0.1004 \\
\hline Biliary stones & 53 & 3.84 & 51 & 3.70 & 0.8415 \\
\hline CKD & 49 & 3.55 & 59 & 4.28 & 0.3263 \\
\hline DM & 138 & 10.00 & 179 & 12.97 & 0.0144 \\
\hline IHD & 97 & 7.03 & 148 & 10.72 & 0.0006 \\
\hline $\mathrm{CHF}$ & 16 & 1.16 & 28 & 2.03 & 0.0682 \\
\hline PAOD & 24 & 1.74 & 21 & 1.52 & 0.6521 \\
\hline \multicolumn{6}{|l|}{ SSRI cDDD } \\
\hline$<28$ & 1380 & 100.00 & - & - & \\
\hline $28-89$ & - & - & 533 & 38.62 & \\
\hline $90-364$ & - & - & 434 & 31.45 & \\
\hline$\geq 365$ & - & - & 413 & 29.93 & \\
\hline \multicolumn{6}{|l|}{ SSRI classification } \\
\hline Citalopram & $\mathrm{II}$ & 0.80 & 474 & 34.35 & $<0.0001$ \\
\hline Escitalopram & 4 & 0.29 & 290 & 21.01 & $<0.0001$ \\
\hline Fluoxetine & 12 & 0.87 & 662 & 47.97 & $<0.0001$ \\
\hline Fluvoxamine & $\mathrm{I}$ & 0.07 & 129 & 9.35 & $<0.000 \mid$ \\
\hline Paroxetine & 6 & 0.43 & 458 & 33.19 & $<0.0001$ \\
\hline Sertraline & 13 & 0.94 & 568 & 41.16 & $<0.0001$ \\
\hline Antiviral drugs & & & & & 0.8401 \\
\hline No & 1328 & 96.23 & 1330 & 96.38 & \\
\hline Yes & 52 & 3.77 & 50 & 3.62 & \\
\hline \multicolumn{6}{|l|}{ Other drugs } \\
\hline Aspirin & 211 & 15.29 & 309 & 22.39 & $<0.0001$ \\
\hline Metformin & 139 & 10.07 & $16 \mid$ & 11.67 & 0.1785 \\
\hline Statins & 185 & $13.4 \mid$ & 253 & 18.33 & 0.0004 \\
\hline
\end{tabular}

Notes: Chi-square test; "2-sample $t$-test. '-' indicates not applicable.

Apprevations: ARD, alcohol-related disease; CHF, congestive heart failure; CKD, chronic kidney disease; cDDD, cumulative defined daily dose; DM, diabetes mellitus; HBV, hepatitis B virus; HTN, hypertension; IHD, ischemic heart disease; PAOD, peripheral arterial occlusive disease; SSRI, selective serotonin reuptake inhibitor.

subjects and an equal number of control non-HCC subjects were analyzed after matching for age and sex. The demographic and baseline comorbidities are shown in Table S1, which includes the medications including SSRI, antiviral drugs, statins, and metformin.

In the logistic regression model, univariate analysis showed an odds ratio (OR) of 0.70 (95\% CI 0.59-0.82, $p<0.0001)$ for SSRI use in HCC occurrence. After adjusting for age, sex, comorbidities, and medications, the adjusted OR was $0.60(95 \%$ CI $0.48-0.75, p<0.0001)$, as shown in Table S2. The further analysis showed that the SSRI presented with a dose-response protective effect for $\mathrm{HCC}$ in the multivariate analysis (28 cDDD, adjusted $\mathrm{OR}=0.73$ [95\% CI 0.51-1.05, $p=0.0904] ; 28-89$ cDDD, adjusted $\mathrm{OR}=0.58$ [95\% CI 0.38 $0.88, p=0.0099] ; 90-364 \mathrm{cDDD}$, adjusted $\mathrm{OR}=0.43[95 \%$ CI $0.27-0.69, p=0.0004] ; \geq 365 \mathrm{cDDD}$, adjusted $\mathrm{OR}=0.63$ [95\% CI 0.39-1.03, $p=0.0654]$ ), and $p$ for trend $<0.0001$, as showed in Table 5. 
Table 2 HRs and $95 \% \mathrm{Cl}$ of HCC for SSRI and non-SSRI users and for other comorbidities

\begin{tabular}{|c|c|c|c|c|c|c|c|}
\hline \multirow[t]{2}{*}{ Characteristics } & \multicolumn{2}{|l|}{ HCC } & \multicolumn{3}{|l|}{ Crude } & \multicolumn{2}{|l|}{ Adjusted } \\
\hline & $(n=33)$ & HR & $(95 \% \mathrm{Cl})$ & $p$-value & HR & $(95 \% \mathrm{Cl})$ & $p$-value \\
\hline \multicolumn{8}{|l|}{$\overline{\text { SSRI }}$} \\
\hline No $(<28$ cDDD) & 24 & 1.00 & Reference & & 1.00 & Reference & \\
\hline Yes ( $\geq 28$ cDDD) & 9 & 0.36 & $(0.17-0.78)$ & 0.0097 & 0.28 & $(0.12-0.64)$ & 0.0027 \\
\hline \multicolumn{8}{|l|}{ Sex } \\
\hline Female & 10 & 1.00 & Reference & & 1.00 & Reference & \\
\hline Male & 23 & 2.37 & $(1.13-4.98)$ & 0.0229 & 1.80 & $(0.8 I-4.01)$ & 0.1489 \\
\hline \multicolumn{8}{|l|}{ Age, years } \\
\hline $18-39$ years & 5 & 1.00 & Reference & & 1.00 & Reference & \\
\hline $40-59$ years & 14 & 2.60 & $(0.93-7.23)$ & 0.0673 & 1.85 & $(0.62-5.48)$ & 0.2672 \\
\hline$\geq 60$ years & 14 & 8.48 & $(3.0 \mathrm{I}-23.87)$ & $<0.000$ I & 4.67 & $(1.32-16.56)$ & 0.0169 \\
\hline \multicolumn{8}{|l|}{ Comorbidities } \\
\hline \multicolumn{8}{|l|}{ ARD } \\
\hline No & 30 & 1.00 & Reference & & 1.00 & Reference & \\
\hline Yes & 3 & 3.88 & $(1.18-12.75)$ & 0.0256 & 1.62 & $(0.44-5.96)$ & 0.4673 \\
\hline \multicolumn{8}{|l|}{ Cirrhosis } \\
\hline No & 21 & 1.00 & Reference & & 1.00 & Reference & \\
\hline Yes & 12 & 25.72 & $(\mid 2.5-52.93)$ & $<0.0001$ & 14.62 & $(6.16-34.72)$ & $<0.000$ I \\
\hline \multicolumn{8}{|l|}{ HTN } \\
\hline No & 16 & 1.00 & Reference & & 1.00 & Reference & \\
\hline Yes & 17 & 4.39 & $(2.21-8.72)$ & $<0.0001$ & 3.07 & $(1.27-7.42)$ & 0.0125 \\
\hline \multicolumn{8}{|l|}{ Hyperlipidemia } \\
\hline No & 32 & 1.00 & Reference & & 1.00 & Reference & \\
\hline Yes & I & 0.23 & $(0.03-1.67)$ & 0.1454 & 0.13 & $(0.02-1.08)$ & 0.0584 \\
\hline \multicolumn{8}{|l|}{ Biliary stones } \\
\hline No & 32 & 1.00 & Reference & & 1.00 & Reference & \\
\hline Yes & I & 0.91 & $(0.12-6.63)$ & 0.9221 & $0.5 \mathrm{I}$ & $(0.06-4)$ & 0.5189 \\
\hline \multicolumn{8}{|l|}{ CKD } \\
\hline No & 30 & 1.00 & Reference & & 1.00 & Reference & \\
\hline Yes & 3 & 3.14 & $(0.95-10.34)$ & 0.0599 & 1.49 & $(0.4 \mathrm{I}-5.48)$ & 0.5494 \\
\hline \multicolumn{8}{|l|}{ DM } \\
\hline No & 28 & 1.00 & Reference & & 1.00 & Reference & \\
\hline Yes & 5 & 1.65 & $(0.64-4.29)$ & 0.3027 & 0.76 & $(0.23-2.56)$ & 0.6618 \\
\hline \multicolumn{8}{|l|}{ IHD } \\
\hline No & 26 & 1.00 & Reference & & 1.00 & Reference & \\
\hline Yes & 7 & 3.16 & $(1.37-7.29)$ & $0.007 \mid$ & 2.35 & $(0.83-6.67)$ & 0.1091 \\
\hline \multicolumn{8}{|l|}{ CHF } \\
\hline No & 29 & 1.00 & Reference & & 1.00 & Reference & \\
\hline Yes & 4 & 12.65 & $(4.39-36.5 I)$ & $<0.0001$ & 2.15 & $(0.61-7.54)$ & 0.2327 \\
\hline \multicolumn{8}{|l|}{ PAOD } \\
\hline No & 31 & 1.00 & Reference & & 1.00 & Reference & \\
\hline Yes & 2 & 5.41 & $(1.28-22.79)$ & 0.0215 & 2.09 & $(0.4 \mid-10.52)$ & 0.373 \\
\hline
\end{tabular}

Notes: Adjusted HR: after adjustment for SSRI use, age, sex, and all comorbidities in Cox proportional hazards regression.

Abbreviations: ARD, alcohol-related disease; CHF, congestive heart failure; $\mathrm{Cl}$, confidence interval; CKD, chronic kidney disease; cDDD, cumulative defined daily dose; DM, diabetes mellitus; HCC, hepatocellular carcinoma; HR, hazard ratio; HTN, hypertension; IHD, ischemic heart disease; PAOD, peripheral occlusive artery disease; SSRI, selective serotonin reuptake inhibitor.

\section{Discussion}

The SSRIs exerted a protective effect on HCC development in HBV-infected patients in a dose-responsive manner after adjusting for potential confounders, including underlying comorbidities and miscellaneous medication (antiviral drugs, metformin, statins, and aspirin), no matter if in cohort study or case-control study designs.
Some studies discussed the relationship between cancer and SSRI use. Coogan et al reported that SSRI exposure reduced the risk of colorectal cancer. ${ }^{21}$ One nationwide study in Finland reported that SSRI use with high cumulative dose resulted in higher risk of breast cancer. But there was no proved association between SSRI use and HCC development. ${ }^{22}$ However, in our study, we found a protective effect 


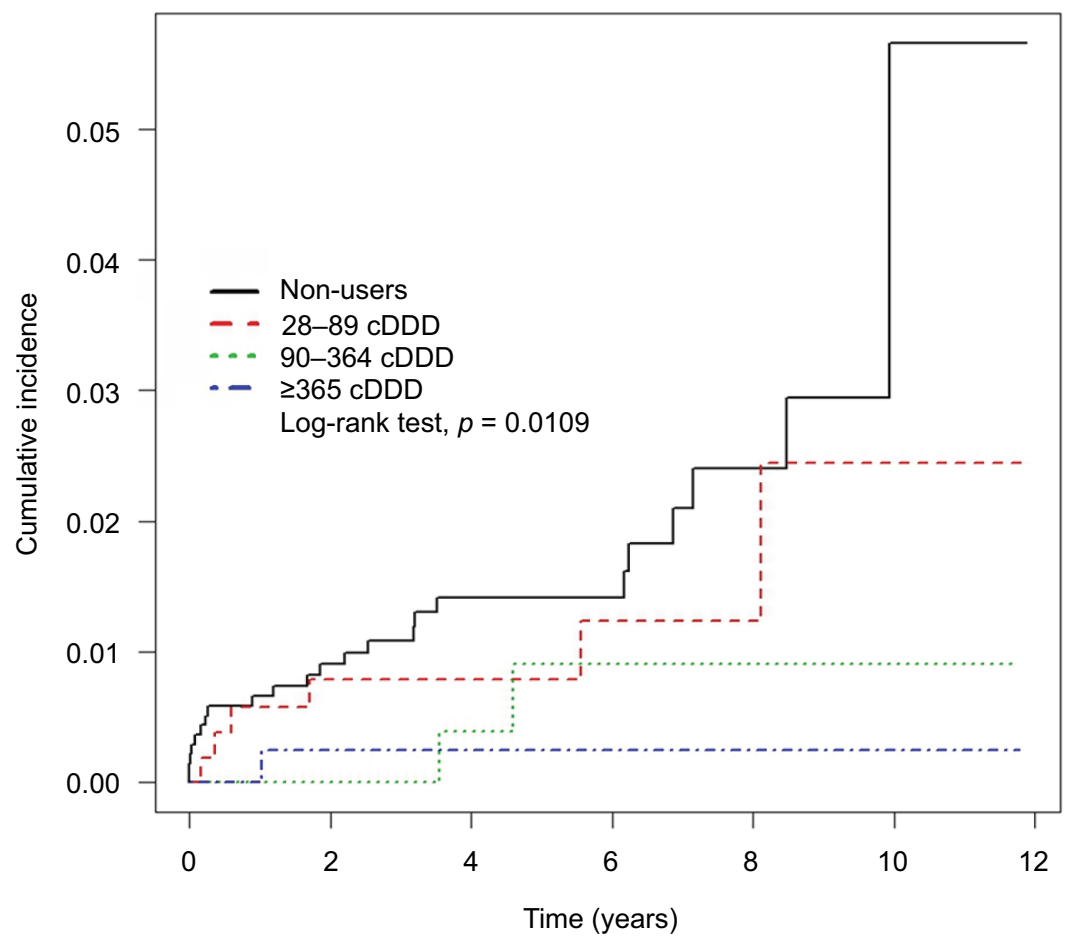

Figure 2 Cumulative incidence of HCC according to the different CDDD of SSRI users during the follow-up period.

Abbreviations: cDDD, cumulative defined daily dose; HCC, hepatocellular carcinoma; SSRI, selective serotonin reuptake inhibitor.

Table 3 Sensitivity analyses of HCC risk for drug combinations

\begin{tabular}{lllllll}
\hline & HR $(95 \% \mathrm{Cl})$ & & & \\
\cline { 2 - 6 } & Crude & Model I & Model 2 & Model 3 & Model 4 & Model 5 \\
\hline Non-SSRI user & $\mathrm{I}$ (reference) & $\mathrm{I}$ (reference) & $\mathrm{I}$ (reference) & $\mathrm{I}$ (reference) & $\mathrm{I}$ (reference) & $\mathrm{I}($ reference) \\
SSRI user & $0.36(0.17-0.78)^{* *}$ & $0.3 \mathrm{I}(0.14-0.66)^{* *}$ & $0.32(0.15-0.69)^{* *}$ & $0.3 \mathrm{I}(0.14-0.66)^{* *}$ & $0.33(0.15-0.70)^{* *}$ & $0.33(0.15-0.7 \mathrm{I})^{* *}$ \\
\hline
\end{tabular}

Notes: Model I, after adjustment for age, sex, and cirrhosis in Cox proportional hazards regression.

Model 2, after adjustment for age, sex, and cirrhosis + anti-viral drugs in Cox proportional hazards regression.

Model 3, after adjustment for age, sex, and cirrhosis + metformin in Cox proportional hazards regression.

Model 4, after adjustment for age, sex, and cirrhosis + statins in Cox proportional hazards regression.

Model 5, after adjustment for age, sex, and cirrhosis + aspirin in Cox proportional hazards regression. ${ }^{* *} p<0.01$.

Abbreviations: $\mathrm{Cl}$, confidence interval; HCC, hepatocellular carcinoma; HR; hazard ratio; SSRI, selective serotonin reuptake inhibitor.

Table 4 HRs and $95 \%$ Cls of HCC associated with different cDDD of SSRI use

\begin{tabular}{|c|c|c|c|c|c|}
\hline \multirow[t]{3}{*}{ Model } & \multirow{3}{*}{$\begin{array}{l}\text { Non-SSRI user } \\
\text { Reference }\end{array}$} & \multicolumn{3}{|l|}{ SSRI user } & \multirow[t]{3}{*}{$p$ for trend } \\
\hline & & 28-89 cDDD & 90-364 cDDD & $\geq 365$ cDDD & \\
\hline & & HR (95\% Cl) & HR (95\% Cl) & HR (95\% Cl) & \\
\hline \multicolumn{6}{|l|}{ Main model } \\
\hline Crude & 1.00 & $0.65(0.26-1.58)$ & $0.28(0.07-1.17)$ & $0.12(0.02-0.90)^{*}$ & 0.0636 \\
\hline Adjusted & 1.00 & $0.5 I(0.21-1.25)$ & $0.22(0.05-0.94)^{*}$ & $0.12(0.02-0.90)^{*}$ & $0.0274 *$ \\
\hline \multicolumn{6}{|c|}{ Main model plus } \\
\hline Antiviral drugs & 1.00 & $0.55(0.22-1.35)$ & $0.22(0.05-0.95)^{*}$ & $0.12(0.02-0.92)^{*}$ & $0.0337^{*}$ \\
\hline Metformin & 1.00 & $0.51(0.21-1.25)$ & $0.22(0.05-0.95)^{*}$ & $0.12(0.02-0.88)^{*}$ & $0.027^{*}$ \\
\hline Statins & 1.00 & $0.53(0.22-1.32)$ & $0.25(0.06-1.05)$ & $0.12(0.02-0.90)^{*}$ & $0.0395^{*}$ \\
\hline Aspirin & 1.00 & $0.53(0.21-1.30)$ & $0.24(0.06-1.02)$ & $0.13(0.02-0.95)^{*}$ & $0.0398 *$ \\
\hline
\end{tabular}

Notes: Main model: after adjustment for age, sex, and cirrhosis in Cox proportional hazards regression. Adjusted HR: after adjustment for SSRI use, age, sex, and cirrhosis in Cox proportional hazards regression. ${ }^{*} p<0.05$

Abbreviations: $\mathrm{Cl}$, confidence interval; $\mathrm{CDDD}$, cumulative defined daily dose; HR, hazard ratio; SSRI, selective serotonin reuptake inhibitor. 
Table 5 Association between SSRI dose in CDDD and OR for HCC

\begin{tabular}{|c|c|c|c|c|c|c|c|c|}
\hline \multirow[t]{2}{*}{ Variable } & \multicolumn{4}{|c|}{ Crude odds ratio } & \multicolumn{4}{|c|}{ Adjusted odds ration } \\
\hline & OR (95\% Cl) & $p$-value & OR $(95 \% \mathrm{Cl})$ & $p$-value & OR (95\% CI) & $p$-value & OR $(95 \% \mathrm{Cl})$ & $p$-value \\
\hline Non-SSRI used & I (reference) & & - & & I (reference) & & - & \\
\hline \multicolumn{9}{|l|}{ SSRI drug used } \\
\hline$<28$ cDDD & $0.83(0.63-1.08)$ & 0.1678 & I (reference) & & $0.73(0.51-1.05)$ & 0.0904 & I (reference) & \\
\hline $28-89$ cDDD & $0.63(0.46-0.86)$ & 0.0037 & $0.76(0.50-1.15)$ & 0.1922 & $0.58(0.38-0.88)$ & 0.0099 & $0.79(0.46-1.34)$ & 0.3893 \\
\hline 90-364 cDDD & $0.62(0.44-0.87)$ & $0.005 I$ & $0.75(0.49-1.15)$ & 0.1828 & $0.43(0.27-0.69)$ & 0.0004 & $0.61(0.35-1.09)$ & 0.0967 \\
\hline$\geq 365$ cDDD & $0.67(0.47-0.97)$ & 0.0323 & $0.8 \mathrm{I}(0.52-1.38)$ & 0.3673 & $0.63(0.39-1.03)$ & 0.0654 & $0.87(0.48-1.58)$ & 0.6463 \\
\hline$p$ for trend & $<0.0001$ & & 0.2726 & & $<0.0001$ & & 0.3454 & \\
\hline
\end{tabular}

Note: ^Model: adjusted for age, sex, alcohol-related disease, cirrhosis, NAFLD, hypertension, hyperlipidemia, biliary stones, CKD, diabetes, CHF, COPD, anti-viral drugs, statin and metformin used. '-' indicates not applicable.

Abbreviations: CDDD, cumulative defined daily dose; $\mathrm{CHF}$, congestive heart failure; $\mathrm{Cl}$, confidence interval; CKD, chronic kidney disease; HCC, hepatocellular carcinoma; NAFLD, nonalcoholic fatty liver disease; OR, odds ratio; SSRI, selective serotonin reuptake inhibitor.

of SSRI on HCC development and this presented in a doseresponsive manner.

In the cell line studies, the effect of SSRIs on HCC is highly controversial. Several studies have reported the protective effect of SSRIs on HCC development. Chen et al indicated that sertraline induced apoptosis in HepG2 cells via the tumor necrosis factor-mitogen-activated protein 4 kinase 4-Jun $\mathrm{N}$-terminal kinase signaling pathway. ${ }^{23}$ Mun et al reported that fluoxetine exhibited apoptotic effects against Hep3B cells through the loss of matrix metalloproteinase, reactive oxygen species (ROS) formation, and the modulation of mitogen-activated protein kinase activities. ${ }^{24}$ Kuwahara et al reported on the anti-tumor effects of SSRIs in human HCC HepG2 cells. ${ }^{25}$

By contrast, several studies have reported the association between SSRIs and HCC. Two major mechanisms contribute to the pathogenesis of SSRI-related HCC development. First, SSRIs exert direct carcinogenic effects on the liver. Second, SSRIs accelerate liver cirrhosis through fibrosis and steatohepatitis formation, and therefore exacerbate HCC development indirectly.

Regarding the direct effects, Liang et al reported that serotonin promoted the proliferation of serum-deprived HCC cells through the up-regulation of fork head box O3a. ${ }^{26}$ Soll et al also reported that serotonin promoted the growth of human HCC. ${ }^{27}$ Regarding the indirect effects of SSRIs, Ruddell et al reported that serotonin fostered liver fibrosis by stimulating stellate cells. ${ }^{28}$ Ebrahimkhani et al indicated that serotonin exacerbated fibrosis by promoting transforming growth factor $\beta 1$ production. ${ }^{29}$ In a murine model of diet-induced steatohepatitis, Nocito et al reported that serotonin increased the production of ROS and lipid peroxides, leading to inflammation and mitochondrial damage, and ultimately, hepatocyte damage. ${ }^{30}$

\section{Strengths}

This study had several strengths. The study cohort was collated using data from a computerized database on randomly sampled HBV-infected patients from all the HBV-infected patients in Taiwan, thus eliminating the possibility of selection bias. In addition, because the data on SSRIs and other medication use were obtained from a historical database from which all the prescription information for the study period were available, the possibility of recall bias can be eliminated. We also clarified possible confounders from different medications. Furthermore, we conducted a sensitivity analysis by using case-control study design. The results showed that SSRI use had a potential protective effect on HCC development in a dose-responsive manner.

\section{Limitations}

Our study had potential limitations. First, we did not obtain any detailed information such as liver ultrasound examination reports or laboratory data such as viral loads. Several unmeasured confounders, including body mass index, alcohol intake, and over-the-counter drug use, which are associated with HCC, are unavailable in the database. However, we used hyperlipidemia and ARD to substitute for obesity and alcohol consumption, respectively, for the adjustment of such potential confounders. Third, we could not verify the exact dosage that the study participants actually took. We presumed that all medications were taken by patients as prescribed, and this may result in overestimating the actual ingested dosage because some degree of non-compliance is always expected. Finally, the sample seems small because of the strict inclusion criteria and matching methods between the study and comparison cohorts. Therefore, we conducted a sensitivity analysis by using case-control study design for the few events of HCC in the cohort study. The results were similar to our 
cohort study. However, the limited number of patients in the study and comparison cohorts made the documented protective effect of statins and metformin in other studies appear non-significant. ${ }^{15,16}$ If this study could be conducted using a cohort of all HBV-infected patients from the NHIRD, in a similar manner to other studies, instead of random samples of 1 million beneficiaries, the protective effect of SSRIs on HCC development could become more evident. ${ }^{15}$

\section{Conclusion}

SSRI use may possibly reduce the risk of HCC in HBVinfected patients in a dose-responsive manner. A further understanding of the underlying mechanisms and studies with a large sample size are warranted.

\section{Acknowledgment}

This study was supported in part by Taiwan Ministry of Health and Welfare Clinical Trial Center (MOHW106-TDUB-212-113004), China Medical University Hospital, Academia Sinica Taiwan Biobank Stroke Biosignature Project (BM10601010036), Taiwan Clinical Trial Consortium for Stroke (MOST 106-2321-B-039-005), Tseng-Lien Lin Foundation, Taichung, Taiwan, Taiwan Brain Disease Foundation, Taipei, Taiwan, and Katsuzo and Kiyo Aoshima Memorial Funds, Japan. The funders had no role in the study design, data collection, analysis, decision to publish, or manuscript preparation. No additional external funding was received for this study.

\section{Disclosure}

The authors report no conflicts of interest in this work.

\section{References}

1. Hoyer D, Clarke DE, Fozard JR, et al. International Union of Pharmacology classification of receptors for 5-hydroxytryptamine (Serotonin). Pharmacol Rev. 1994;46(2):157-203.

2. Wu CS, Shau WY, Chan HY, Lee YC, Lai YJ, Lai MS. Utilization of antidepressants in Taiwan: a nationwide population-based survey from 2000 to 2009. Pharmacoepidemiol Drug Saf. 2012;21(9):980-988.

3. Huskamp HA, Donohue JM, Koss C, Berndt ER, Frank RG. Generic entry, reformulations and promotion of SSRIs in the US. Pharmacoeconomics. 2008;26(7):603-616.

4. Beasley RP, Hwang LY, Lin CC, Chien CS. Hepatocellular carcinoma and hepatitis B virus. A prospective study of 22707 men in Taiwan. Lancet. 1981;2(8256):1129-1133.

5. Yu MW, Chen CJ. Hepatitis B and C viruses in the development of hepatocellular carcinoma. Crit Rev Oncol Hematol. 1994;17(2): 71-91.

6. Chen JD, Yang HI, Iloeje UH, et al; Risk Evaluation of Viral Load Elevation and Associated Liver Disease/Cancer in HBV (REVEAL-HBV) Study Group. Carriers of inactive hepatitis B virus are still at risk for hepatocellular carcinoma and liver-related death. Gastroenterology. 2010;138(5): 1747-1754.
7. Huang YW, Hu JT, Hu FC, et al. Biphasic pattern of depression and its predictors during pegylated interferon-based therapy in chronic hepatitis B and C patients. Antivir Ther. 2013;18(4):567-573.

8. Chen WC, Lai HC, Su WP, Palani M, Su KP. Bupropion for interferonalpha-induced depression in patients with hepatitis $\mathrm{C}$ viral infection: an open-label study. Psychiatry Investig. 2015;12(1):142-145.

9. Shah H, Kadia S, Bawa R, Lippmann S. Management of depression induced by interferon hepatitis therapies. Prim Care Companion CNS Disord. 2013;15(5):PCC.12r01487.

10. Nelligan JA, Loftis JM, Matthews AM, Zucker BL, Linke AM, Hauser P. Depression comorbidity and antidepressant use in veterans with chronic hepatitis C: results from a retrospective chart review. J Clin Psychiatry. 2008;69(5):810-816.

11. Bianchi G, Marchesini G, Nicolino F, et al. Psychological status and depression in patients with liver cirrhosis. Dig Liver Dis. 2005;37(8): 593-600.

12. Chen VC, Lin CF, Hsieh YH, et al. Hepatocellular carcinoma and antidepressants: a nationwide population-based study. Oncotarget. 2017;8(18):30464-30470.

13. Chan HL, Chiu WC, Chen VC, et al. SSRIs associated with decreased risk of hepatocellular carcinoma: a population-based case-control study. Psychooncology. Epub 2017 Jun 30.

14. Lai MN, Wang SM, Chen PC, Chen YY, Wang JD. Populationbased case-control study of Chinese herbal products containing aristolochic acid and urinary tract cancer risk. J Natl Cancer Inst. 2010;102(3):179-186.

15. Tsan YT, Lee CH, Ho WC, Lin MH, Wang JD, Chen PC. Statins and the risk of hepatocellular carcinoma in patients with hepatitis $\mathrm{C}$ virus infection. J Clin Oncol. 2013;31(12):1514-1521.

16. Tsan YT, Lee CH, Wang JD, Chen PC. Statins and the risk of hepatocellular carcinoma in patients with hepatitis B virus infection. J Clin Oncol. 2012;30(6):623-630.

17. Wu CY, Wu MS, Kuo KN, Wang CB, Chen YJ, Lin JT. Effective reduction of gastric cancer risk with regular use of nonsteroidal antiinflammatory drugs in Helicobacter pylori-infected patients. J Clin Oncol. 2010;28(18):2952-2957.

18. Wu CY, Kuo KN, Wu MS, Chen YJ, Wang CB, Lin JT. Early Helicobacter pylori eradication decreases risk of gastric cancer in patients with peptic ulcer disease. Gastroenterology. 2009;137(5):1641-1648. e1641-1642.

19. Wu CY, Chen YJ, Ho HJ, et al. Association between nucleoside analogues and risk of hepatitis B virus-related hepatocellular carcinoma recurrence following liver resection. JAMA. 2012;308(18): 1906-1914.

20. Chen HH, Lin MC, Muo CH, Yeh SY, Sung FC, Kao CH. Combination therapy of metformin and statin may decrease hepatocellular carcinoma among diabetic patients in Asia. Medicine (Baltimore). 2015;94(24):e1013.

21. Coogan PF, Strom BL, Rosenberg L. Antidepressant use and colorectal cancer risk. Pharmacoepidemiol Drug Saf. 2009;18(11):1111-1114.

22. Haukka J, Sankila R, Klaukka T, et al. Incidence of cancer and antidepressant medication: record linkage study. Int J Cancer. 2010;126(1): 285-296.

23. Chen S, Xuan J, Wan L, et al. Sertraline, an antidepressant, induces apoptosis in hepatic cells through the mitogen-activated protein kinase pathway. Toxicol Sci. 2014;137(2):404-415.

24. Mun AR, Lee SJ, Kim GB, Kang HS, Kim JS, Kim SJ. Fluoxetineinduced apoptosis in hepatocellular carcinoma cells. Anticancer Res. 2013;33(9):3691-3697.

25. Kuwahara J, Yamada T, Egashira N, et al. Comparison of the anti-tumor effects of selective serotonin reuptake inhibitors as well as serotonin and norepinephrine reuptake inhibitors in human hepatocellular carcinoma cells. Biol Pharm Bull. 2015;38(9):1410-1414.

26. Liang $\mathrm{C}$, Chen W, Zhi X, et al. Serotonin promotes the proliferation of serum-deprived hepatocellular carcinoma cells via upregulation of FOXO3a. Mol Cancer. 2013;12:14. 
27. Soll C, Jang JH, Riener MO, et al. Serotonin promotes tumor growth in human hepatocellular cancer. Hepatology. 2010;51(4): 1244-1254.

28. Ruddell RG, Oakley F, Hussain Z, et al. A role for serotonin (5-HT) in hepatic stellate cell function and liver fibrosis. Am J Pathol. 2006;169(3):861-876.
29. Ebrahimkhani MR, Oakley F, Murphy LB, et al. Stimulating healthy tissue regeneration by targeting the $5-\mathrm{HT}_{2} \mathrm{~B}$ receptor in chronic liver disease. Nat Med. 2011;17(12):1668-1673.

30. Nocito A, Dahm F, Jochum W, et al. Serotonin mediates oxidative stress and mitochondrial toxicity in a murine model of nonalcoholic steatohepatitis. Gastroenterology. 2007;133(2):608-618. 


\section{Supplementary materials}

Table SI Data of cases and controls

\begin{tabular}{|c|c|c|c|c|c|}
\hline \multirow[t]{2}{*}{ Variable } & \multicolumn{2}{|c|}{ Control group $(\mathrm{N}=9070)$} & \multicolumn{2}{|c|}{ HCC group $(\mathrm{N}=9070)$} & \multirow[t]{2}{*}{$p$-value } \\
\hline & $\bar{n}$ & $\%$ & $\bar{n}$ & $\%$ & \\
\hline \multicolumn{6}{|l|}{ SSRI drug used } \\
\hline No & 8691 & 95.82 & 8803 & 97.06 & $<0.0001$ \\
\hline Yes & 379 & 4.18 & 267 & 2.94 & \\
\hline$<28$ cDDD & 117 & 1.29 & 98 & 1.08 & \\
\hline $28-89$ cDDD & 102 & 1.12 & 65 & 0.72 & \\
\hline $90-364$ cDDD & 88 & 0.97 & 55 & 0.61 & \\
\hline$\geq 365$ cDDD & 72 & 0.79 & 49 & 0.54 & \\
\hline Sex & & & & & 0.99 \\
\hline Female & 2039 & 22.48 & 2039 & 22.48 & \\
\hline Male & 7031 & 77.52 & 7031 & 77.52 & \\
\hline Age, years (SD) & 53.12 & & 53.42 & & 0.1456 \\
\hline 20-29 years & 192 & 2.12 & 192 & 2.12 & 0.99 \\
\hline $30-39$ years & 969 & 10.68 & 969 & 10.68 & \\
\hline $40-49$ years & 2798 & 30.85 & 2798 & 30.85 & \\
\hline $50-59$ years & 2610 & 28.78 & 2610 & 28.78 & \\
\hline$\geq 60$ years & 2501 & 27.57 & 2501 & 27.57 & \\
\hline \multicolumn{6}{|l|}{ Comorbidity } \\
\hline Alcohol-related disease & 356 & 3.93 & $|18|$ & 13.02 & $<0.000$ I \\
\hline Cirrhosis & 598 & 6.59 & 5997 & 66.12 & $<0.0001$ \\
\hline NAFLD & 475 & 5.24 & 337 & 3.72 & $<0.0001$ \\
\hline Hypertension & 3242 & 35.74 & 2942 & 32.44 & $<0.0001$ \\
\hline Hyperlipidemia & 2655 & 29.27 & 1518 & 16.74 & $<0.0001$ \\
\hline Biliary stones & 647 & 7.13 & 916 & 10.1 & $<0.000$ I \\
\hline CKD & 598 & 6.59 & 857 & 9.45 & $<0.0001$ \\
\hline Diabetes & 1826 & 20.13 & 2085 & 22.99 & $<0.0001$ \\
\hline $\mathrm{CHF}$ & 263 & 2.90 & 340 & 3.75 & $<0.0001$ \\
\hline COPD & 1742 & 19.21 & 1101 & 12.14 & $<0.0001$ \\
\hline \multicolumn{6}{|l|}{ Anti-viral drugs } \\
\hline No & 8836 & 97.42 & 7975 & 87.93 & $<0.0001$ \\
\hline Yes & 234 & 2.58 & 1095 & 12.07 & \\
\hline \multicolumn{6}{|l|}{ Statin } \\
\hline No & 7677 & 84.64 & 8067 & 88.94 & $<0.000$ I \\
\hline Yes & 1393 & 15.36 & 1003 & 11.06 & \\
\hline \multicolumn{6}{|l|}{ Metformin } \\
\hline No & 424 & 4.67 & 189 & 2.08 & $<0.0001$ \\
\hline Yes & 8646 & 95.33 & 8881 & 97.92 & \\
\hline
\end{tabular}

Notes: Chi-square test; ${ }^{2}$-sample $t$-test.

Abbreviations: CDDD, cumulative defined daily dose; CHF, congestive heart failure; CKD, chronic kidney disease; HCC, hepatocellular carcinoma; NAFLD, nonalcoholic fatty liver disease; SSRI, selective serotonin reuptake inhibitor. 
Table S2 ORs ratios for HCC

\begin{tabular}{|c|c|c|c|c|}
\hline \multirow[t]{2}{*}{ Variable } & \multicolumn{2}{|l|}{ Crude odds ratio } & \multicolumn{2}{|c|}{ Adjusted odds ratio^^^} \\
\hline & OR $(95 \% \mathrm{Cl})$ & $p$-value & OR (95\% Cl) & $p$-value \\
\hline \multicolumn{5}{|l|}{ SSRI drug used } \\
\hline No & I (reference) & & I (reference) & \\
\hline Yes & $0.70(0.59-0.82)$ & $<0.0001$ & $0.60(0.48-0.75)$ & $<0.0001$ \\
\hline \multicolumn{5}{|l|}{ Sex } \\
\hline Female & I (reference) & & I (reference) & \\
\hline Male & $1.00(0.93-1.07)$ & 0.999 & $0.84(0.76-0.92)$ & 0.0003 \\
\hline \multicolumn{5}{|l|}{ Age, years $(\mathrm{SD})^{\#}$} \\
\hline $20-29$ years & I (reference) & & I (reference) & \\
\hline $30-39$ years & $1.00(0.80-1.25)$ & 0.99 & $0.82(0.64-1.05)$ & 0.1182 \\
\hline $40-49$ years & $1.00(0.81-1.23)$ & 0.99 & $0.69(0.55-0.87)$ & 0.0019 \\
\hline $50-59$ years & $1.00(0.8 \mathrm{I}-\mathrm{I} .23)$ & 0.99 & $0.62(0.49-0.79)$ & $<0.0001$ \\
\hline$\geq 60$ years & $1.00(0.81-1.23)$ & 0.99 & $0.63(0.49-0.80)$ & 0.0002 \\
\hline \multicolumn{5}{|l|}{ Comorbidity } \\
\hline Alcohol-related disease & $3.66(3.24-4.14)$ & $<0.0001$ & $1.04(0.88-1.24)$ & 0.6209 \\
\hline Cirrhosis & $27.65(25.18-30.36)$ & $<0.0001$ & $26.54(24-29.35)$ & $<0.0001$ \\
\hline NAFLD & $0.70(0.6 \mathrm{I}-0.8 \mathrm{I})$ & $<0.0001$ & $0.78(0.64-0.94)$ & 0.0104 \\
\hline Hypertension & $0.86(0.81-0.92)$ & $<0.0001$ & $0.93(0.84-1.02)$ & 0.118 \\
\hline Hyperlipidemia & $0.49(0.45-0.52)$ & $<0.000$ I & $0.49(0.44-0.55)$ & $<0.0001$ \\
\hline Biliary stones & $1.46(1.32-1.63)$ & $<0.0001$ & $1.13(0.98-1.31)$ & 0.0929 \\
\hline CKD & $1.48(1.33-1.65)$ & $<0.0001$ & $1.38(1.18-1.60)$ & $<0.0001$ \\
\hline Diabetes & $1.18(1.10-1.27)$ & $<0.0001$ & $1.30(1.17-1.45)$ & $<0.0001$ \\
\hline $\mathrm{CHF}$ & $1.30(1.11-1.54)$ & $<0.0001$ & I.I8(0.94-I.49) & 0.1609 \\
\hline COPD & $0.58(0.54-0.63)$ & $<0.0001$ & $0.54(0.48-0.6 I)$ & $<0.0001$ \\
\hline \multicolumn{5}{|l|}{ Antiviral drugs } \\
\hline No & I (reference) & & I (reference) & \\
\hline Yes & $1.65(1.50-1.80)$ & $<0.0001$ & $2.04(1.70-2.44)$ & $<0.0001$ \\
\hline \multicolumn{5}{|l|}{ Statin } \\
\hline No & I (reference) & & I (reference) & \\
\hline Yes & $0.69(0.63-0.75)$ & $<0.0001$ & $1.09(0.95-1.26)$ & 0.2116 \\
\hline \multicolumn{5}{|l|}{ Metformin } \\
\hline No & I (reference) & & I (reference) & \\
\hline Yes & $2.30(1.94-2.74)$ & $<0.0001$ & $2.70(2.13-3.44)$ & $<0.0001$ \\
\hline
\end{tabular}

Notes: ^^Estimated odds ratio by logistic regression model. "2-sample t-test.

Abbreviations: CHF, congestive heart failure; CI, confidence interval; CKD, chronic kidney disease; HCC, hepatocellular carcinoma; NAFLD, nonalcoholic fatty liver disease; OR, odds ratio; SSRI, selective serotonin reuptake inhibitor.

Cancer Management and Research

\section{Publish your work in this journal}

Cancer Management and Research is an international, peer-reviewed open access journal focusing on cancer research and the optimal use of preventative and integrated treatment interventions to achieve improved outcomes, enhanced survival and quality of life for the cancer patient. The manuscript management system is completely online and includes

\section{Dovepress}

a very quick and fair peer-review system, which is all easy to use. Visit http://www.dovepress.com/testimonials.php to read real quotes from published authors. 